\title{
Financial Asset Returns, Direction-of-Change Forecasting, and Volatility Dynamics
}

\author{
Peter F. Christoffersen \\ Faculty of Management, McGill University, 1001 Sherbrooke Street West, Montreal, Quebec, Canada H3A 1G5 and \\ Centre for Interuniversity Research and Analysis on Organizations (CIRANO), Montreal, Quebec, Canada, peter.christoffersen@mcgill.ca
}

Francis X. Diebold

Department of Economics, University of Pennsylvania, 3718 Locust Walk, Philadelphia, Pennsylvania 19104-6297 and National Bureau of Economic Research, Cambridge, Massachusetts, fdiebold@wharton.upenn.edu

\begin{abstract}
W e consider three sets of phenomena that feature prominently in the financial economics literature: (1) conditional mean dependence (or lack thereof) in asset returns, (2) dependence (and hence forecastability) in asset return signs, and (3) dependence (and hence forecastability) in asset return volatilities. We show that they are very much interrelated and explore the relationships in detail. Among other things, we show that (1) volatility dependence produces sign dependence, so long as expected returns are nonzero, so that one should expect sign dependence, given the overwhelming evidence of volatility dependence; (2) it is statistically possible to have sign dependence without conditional mean dependence; (3) sign dependence is not likely to be found via analysis of sign autocorrelations, runs tests, or traditional market timing tests because of the special nonlinear nature of sign dependence, so that traditional market timing tests are best viewed as tests for sign dependence arising from variation in expected returns rather than from variation in volatility or higher moments; (4) sign dependence is not likely to be found in very high-frequency (e.g., daily) or very low-frequency (e.g., annual) returns; instead, it is more likely to be found at intermediate return horizons; and (5) the link between volatility dependence and sign dependence remains intact in conditionally non-Gaussian environments, for example, with time-varying conditional skewness and/or kurtosis.
\end{abstract}

Key words: return sign dependence, market timing; prediction

History: Accepted by David Hsieh, finance; received February 25, 2004. This paper was with the authors

9 months for 3 revisions.

\section{Introduction}

We consider three sets of phenomena that feature prominently in the financial economics literature: (1) approximate conditional mean independence (and hence little or no forecastability) in asset returns, (2) dependence (and hence forecastability) in asset return signs, and (3) dependence (and hence forecastability) in asset return volatilities. We argue that they are very much interrelated, forming a tangled and intriguing web, a full understanding of which leads to a deeper understanding of the subtleties of financial market dynamics. Let us introduce them in turn.

First, consider conditional mean independence, by which we mean that an asset return's conditional mean does not vary with the conditioning information set. Approximate conditional mean independence then implies that out-of-sample return forecasting will be difficult, if not impossible. This view is widely held and stems from both introspection and observation. That is, financial economic theory suggests that asset returns should not be easily forecast using readily available information and forecasting techniques, and a broad interpretation of four decades of empirical work suggests that the data support the theory (e.g., Fama 1970, 1991). Consequently, we believe that conditional mean independence is reasonably viewed as a good working approximation to asset return dynamics. ${ }^{1}$

Second, consider dependence and hence forecastability of market direction (the return sign). Profitable trading strategies result from successful forecasting of market direction, quite apart from whether one is successful at forecasting returns themselves. A wellknown and classic example, discussed routinely even

\footnotetext{
${ }^{1}$ We emphasize the word "approximation" because weak conditional mean dependence may appear at both long horizons (e.g., Fama and French 1988, 1989; Campbell and Shiller 1988) and short horizons (e.g., Lo and MacKinlay 1999) for a variety of reasons, ranging from low-frequency variation in risk premia to highfrequency variation in market microstructure noise. The evidence of long-horizon conditional mean dependence remains controversial, however, because of serious statistical complications including possibly spurious regressions (e.g., Kirby 1997), data snooping biases (e.g., Foster et al. 1997), and small sample biases (Nelson and Kim 1993), which may distort standard inference procedures when applied to long-horizon prediction regressions.
} 
at the MBA textbook level (e.g., Levich 2001, Chapter 8), involves trading in speculative markets. If, for example, the yen-dollar exchange rate is expected to increase, reflecting expected depreciation of the yen relative to the dollar, and hence a negative expected return on the yen, one would sell yen for dollar, whether in the spot or derivatives markets. Positive profits will be made when the sign forecast is correct. Generalizations to multiple asset classes, such as stock and bond markets, involve basing allocation strategies on forecasts of the sign of the return spread. Recent literature shows that asset return sign forecasting can often be done with surprising success; see, among others, Breen et al. (1989), Leitch and Tanner (1991), Wagner et al. (1992), Pesaran and Timmermann (1995), Kuan and Liu (1995), Larsen and Wozniak (1995), Womack (1996), Gencay (1998), Leung et al. (2000), Elliott and Ito (1999), White (2000), Pesaran and Timmermann (2004), and Cheung et al. (2005).

Finally, consider dependence and forecastability of asset return volatility. A huge literature documents the notable dependence, and hence forecastability, of asset return volatility, with important implications not only for asset allocation, but also for asset pricing and risk management. Bollerslev et al. (1992) provide a fine review of evidence in the GARCH tradition, while Ghysels et al. (1996) survey results from stochastic volatility modeling, Franses and van Dijk (2000) survey results from regime-switching volatility models, and Andersen et al. (2005a) survey results from realized volatility modeling. Interesting extensions include models of time variation in higherordered conditional moments, such as the conditional skewness models of Harvey and Siddique (2000) and the conditional density model of Hansen (1994). The recent literature also contains intriguing theoretical work explaining the empirical phenomenon of volatility forecastability, such as Brock and Hommes (1997) and de Fontnouvelle (2000).

In this paper, we characterize in detail the relationships among the three phenomena and three literatures discussed briefly above: (1) asset return conditional mean independence, (2) sign dependence, and (3) conditional variance dependence. It is well known that conditional mean independence and conditional variance dependence are statistically compatible. However, much less is known in general about sign dependence, and in particular about the relationship of sign dependence to conditional mean independence and volatility dependence. Hence, we focus throughout on sign dependence. Among other things, we show that

(1) Volatility dependence produces sign dependence, so long as expected returns are nonzero. Hence, one should expect sign dependence, given the overwhelming evidence of volatility dependence.
(2) It is statistically possible to have sign (and volatility) dependence, while at the same time, mean independence.

(3) Sign dependence is not likely to be found via analysis of sign autocorrelations or other tests (such as runs tests or traditional tests of market timing) because the nature of sign dependence is highly nonlinear.

(4) Sign dependence is not likely to be found in high-frequency (e.g., daily) or low-frequency (e.g., annual) returns. Instead, it is more likely to appear at intermediate return horizons of two or three months.

(5) The link between volatility forecastability and sign forecastability remains intact in conditionally non-Gaussian environments, for example, with timevarying conditional skewness and/or kurtosis; in fact, it is significantly enriched.

We derive results (1), (2), and (5) theoretically in a general setting, we derive (3) and (4) via a complementary calibrated simulation experiment using a popular model of return dynamics, and we provide a preliminary empirical exploration using the S\&P 500 in conjunction with RiskMetrics volatility forecasts.

Before moving on, we wish to emphasize that our basic contention, namely, that sign dependence exists and has fundamental connections to volatility dependence, in no way requires conditional mean independence; instead, we simply invoke conditional mean independence to make our point as clearly as possible. This is fortunate because although conditional mean independence is a reasonable approximation for many purposes, it is also the subject of some controversy on both the theoretical and empirical fronts, with both theory and empirics ultimately proving inconclusive. Classical dynamic asset pricing theory predicts a positive equilibrium relationship between conditional first and second moments (e.g., Merton 1973, Ferson and Harvey 1991), but it is now recognized that theory is also consistent with a negative relationship (e.g., Abel 1988, Backus and Gregory 1993, Gennotte and Marsh 1993). Similarly inconclusive results hold on the empirical side: positive but often insignificant dependence is found in Baillie and DeGennaro (1990), French et al. (1987), Campbell and Hentschel (1992), and Ghysels et al. (2005), whereas negative dependence is found in Campbell (1987), Nelson (1991), Lettau and Ludvigson (2005), and Brandt and Kang (2004), and both are found in Glosten et al. (1993), Harvey (2001), and Turner et al. (1989).

We proceed as follows. In $\$ 2$, we build intuition by sketching the main results in simple contexts, focusing primarily on the conditionally Gaussian case. We discuss the basic framework, we arrive at the basic result that volatility dynamics produce sign dynamics, and we draw the implications. In $\S \S 3$ and 4 , we focus in greater depth on sign dependence, and we 
provide basic results on sign realizations, sign forecasts, and the relation between the two, stressing both the measurement $(\S 3)$ and detection $(\$ 4)$ of sign forecastability. In $\$ 5$, we perform a detailed simulation experiment, which not only illustrates our basic results but also extends them significantly, by characterizing the nature of sign forecastability as a function of forecast horizon. We provide an illustrative empirical application in §6, and conclude in $\$ 7$.

\section{Conditional Mean Dependence, Sign Dependence, and Volatility Dependence: Basic Results}

Here, we explore the links between conditional mean dependence, sign dependence, and volatility dependence. We have used the terms repeatedly, but thus far, not defined them precisely, relying instead on readers' intuition, so let us begin with some precise definitions. First, we will say that a return series $R_{t+1}$ displays conditional mean dependence (conditional mean dynamics, conditional mean forecastability, conditional mean predictability) if $E\left(R_{t+1} \mid \Omega_{t}\right)$ varies with $\Omega_{t}{ }^{2}$ Second, we will say that $R_{t+1}$ displays sign dependence (sign dynamics, sign forecastability, sign predictability) if the return sign indicator series $I\left(R_{t+1}>0\right)$ displays conditional mean dependence; that is, if $E\left(I\left(R_{t+1}>0\right) \mid \Omega_{t}\right)$ varies with $\Omega_{t}{ }^{3}$ Finally, we will say that $R_{t+1}$ displays conditional variance dependence (conditional variance dynamics, conditional variance forecastability, conditional variance predictability, volatility dependence, volatility dynamics, volatility forecastability, volatility predictability) if $\sigma_{t+1 \mid t}^{2} \equiv \operatorname{Var}\left(R_{t+1} \mid \Omega_{t}\right)$ varies with $\Omega_{t}$.

We now proceed to characterize the relationships among sign, volatility dynamics, and conditional mean dynamics.

\subsection{Sign Dynamics Follow from Volatility Dynamics}

Consider the prevalence of volatility dynamics in high-frequency asset returns, and the positive expected returns earned on risky assets. To take the simplest possible example, which nevertheless conveys all of the basic points, assume that the returns on a generic risky asset are distributed as

$$
R_{t+1} \mid \Omega_{t} \sim N\left(\mu, \sigma_{t+1 \mid t}^{2}\right), \quad \mu>0,
$$

\footnotetext{
${ }^{2}$ Here and throughout, "returns" are excess returns relative to the risk-free rate.

${ }^{3}$ Equivalently, $R_{t+1}$ displays sign dependence if the conditional probability of a positive return, $\operatorname{Pr}\left(R_{t+1}>0 \mid \Omega_{t}\right)$, varies with $\Omega_{t}$ because $\operatorname{Pr}\left(R_{t+1}>0 \mid \Omega_{t}\right)=E\left(I\left(R_{t+1}\right)>0 \mid \Omega_{t}\right)$.
}

and therefore display conditional variance dependence but no conditional mean dependence. The probability of a positive return is then

$$
\begin{aligned}
\operatorname{Pr}_{t}\left(R_{t+1}>0\right) & =1-\operatorname{Pr}_{t}\left(R_{t+1}<0\right) \\
& =1-\operatorname{Pr}\left(\frac{R_{t+1}-\mu}{\sigma_{t+1 \mid t}}<\frac{-\mu}{\sigma_{t+1 \mid t}}\right) \\
& =\Phi\left(\frac{\mu}{\sigma_{t+1 \mid t}}\right),
\end{aligned}
$$

where $\Phi(\cdot)$ is the $N(0,1)$ cumulative density function (c.d.f.). Note that although the distribution is symmetric around the conditional mean, and the conditional mean is constant by assumption, the sign of the return is nevertheless forecastable because the probability of a positive return is time varying (and above 0.5 if $\mu>$ 0 ). As volatility moves, so too does the probability of a positive return: the higher the volatility, the lower the probability of a positive return, as illustrated in Figure 1.

The surprising result that the sign of the return is forecastable although the conditional mean is constant hinges interestingly on the interaction of a nonzero mean return and nonconstant volatility. A zero mean would render the sign unforecastable, as would constant volatility; hence the tradition in financial econometrics of removing unconditional means and working with zero-mean series disguises sign forecastability. Note also that a large volatility relative to the mean renders the sign nearly unpredictable. It is interesting to note that the key link between sign forecastability and volatility dynamics parallels the literature on optimal prediction under asymmetric loss. In sign forecasting, volatility dynamics interact with a nonzero mean to produce time variation in the probability of a positive return, and hence sign forecastability. In forecasting under asymmetric loss, as in Christoffersen and Diebold $(1996,1997)$, volatility dynamics similarly produce time variation in the optimal point forecast of a series with a constant conditional mean.

Our setup above was intentionally simple, but it is easy to see that the results are maintained under a number of interesting variations. To take just one example (we discuss several in the online supplement on the Management Science website at http://mansci. pubs.informs.org/ecompanion.html), note that if returns are conditionally non-Gaussian (e.g., conditionally skewed), the result in Equation (2) that volatility forecastability implies sign forecastability still holds.

\subsection{Sign Dynamics Do Not Require Conditional Mean Dynamics}

Forecasting market direction is of interest for active asset allocation, and a substantial body of evidence 
Figure 1 The Dependence of Sign Probability on Volatility

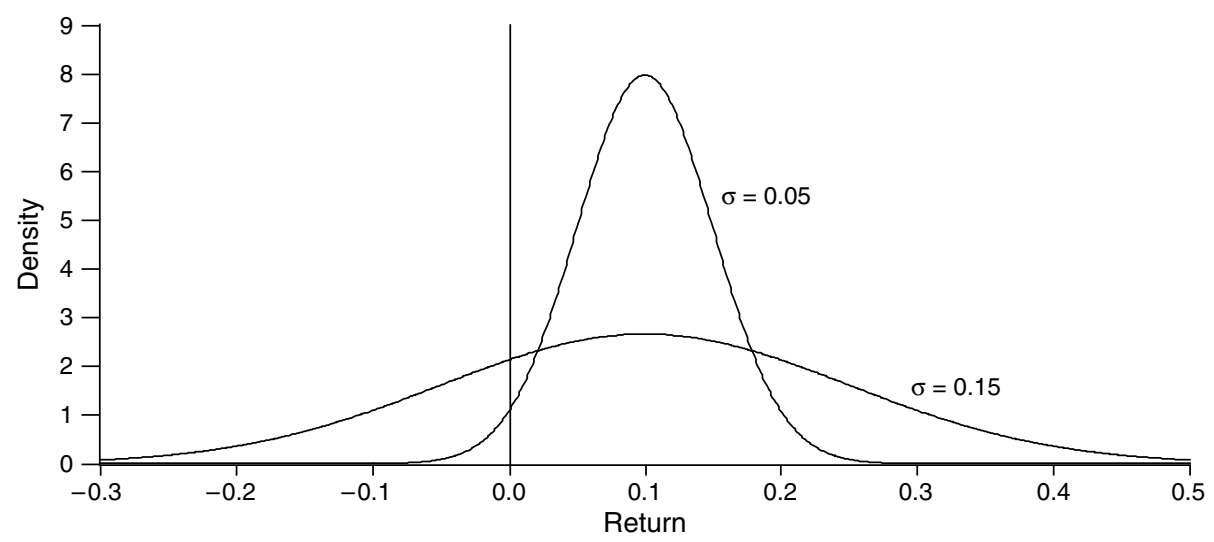

Notes. We show two Gaussian return densities, each with expected return of $10 \%$. The first return has a standard deviation of $5 \%$, and hence is positive with probability 0.98 (the area to the right of zero under the more-peaked density function). The second return has a standard deviation of $15 \%$, and hence is positive with smaller probability 0.75 (the area to the right of zero under the less-peaked density function).

suggests that it can be done, as per the references given earlier. Successful directional forecasting implies that returns must be somehow dependent. When directional forecasting is found to be empirically successful, it is tempting to assert that it is driven by (perhaps subtle) nonlinear conditional mean dependence, which would be missed in standard analyses of (linear) dependence, such as those based on return autocorrelations.

The key insight is that although sign dynamics could be due to conditional mean dependence, they need not be. In particular, we have demonstrated that volatility dynamics produce sign dynamics, so that one should expect sign dynamics in asset returns, given the overwhelming evidence of volatility dynamics, even if returns display near conditional mean independence.

Moreover, as noted above, in a general equilibrium involving risk-averse market participants observed prices will, of course, not in general evolve as martingales, which is to say that observed returns may in general display some conditional mean dynamics because of perhaps time-varying risk premia over the business cycle. Any such conditional mean dynamics may, of course, contribute to sign forecastability as well. In our analysis, we intentionally assume the absence of conditional mean dynamics for several reasons. First, as discussed earlier, the evidence suggests that conditional mean independence is a reasonable empirical approximation to asset return dynamics, despite the fact that dynamic asset pricing theory predicts dependence between first and second moments. Second, we want to focus on the subtle and little-understood connection between sign dynamics and volatility dynamics. Third, standard expansions suggest that even if conditional mean dynamics are operative, one may expect that conditional variance dynamics will dominate. ${ }^{4}$ To see this, consider a Taylor series expansion of $\mu_{t+1 \mid t} / \sigma_{t+1 \mid t}$ about the mean

$$
\begin{aligned}
\mu_{t+1 \mid t} / \sigma_{t+1 \mid t} \approx \mu / \sigma+\left(\mu_{t+1 \mid t}-\mu\right) \sigma^{-1} \\
+\left(\sigma_{t+1 \mid t}^{-1}-\sigma^{-1}\right) \mu .
\end{aligned}
$$

Based on this, consider the variance of $\mu_{t+1 \mid t} / \sigma_{t+1 \mid t}$. To first order, the variance of $\mu_{t+1 \mid t}$ is multiplied by $\sigma^{-2}$, which is a large number, while the variance of $1 / \sigma_{t+1 \mid t}$ is multiplied by $\mu^{2}$, a smaller number. However, the variance of $1 / \sigma_{t+1 \mid t}$ is huge and should be the dominant term.

\subsection{An Intriguing Decomposition}

It is interesting to interpret the phenomena at hand through the decomposition ${ }^{5}$

$$
R_{t+1}=\operatorname{sign}\left(R_{t+1}\right) \cdot\left|R_{t+1}\right| \cdot
$$

In the simple models just described (and, to a good approximation, in observed return data), both of the right-hand side components of returns display persistent dynamics and hence are forecastable, yet the left-hand side variable, returns themselves, are unforecastable. This is an example of a nonlinear "common feature," in the terminology of Engle and Kozicki (1993): both signs of returns and absolute returns are conditional mean dependent and hence forecastable, yet their product can be conditional mean independent, and hence unforecastable.

\footnotetext{
${ }^{4}$ The authors thank a referee for suggesting this, and for the Taylor series argument.

${ }^{5}$ See Rydberg and Shephard (2003) for an extensive and authoritative treatment of this and related decompositions in the context of ultrahigh-frequency financial asset price movements.
} 


\section{Measuring the Strength of Sign Forecastability}

Here, we examine a number of questions relevant to measuring sign forecastability. How, if at all, does the derivative of a sign forecast with respect to volatility vary as a function of volatility, and in what volatility region is the derivative largest? What is the correlation between sign forecasts and realizations, and how, if at all, is the correlation related to the volatility of sign forecasts?

\subsection{The Responsiveness of Sign Forecasts to Volatility Changes}

In the simple setup developed thus far, we achieve probability forecastability only from volatility dynamics. A key issue is how much the probability forecast changes when the volatility changes, and the obvious measure is the derivative

$$
\Re=\frac{\partial \operatorname{Pr}_{t}\left(R_{t+1}>0\right)}{\partial \sigma_{t+1 \mid t}},
$$

where we choose the notation $\Re$ for "responsiveness." ${ }^{16}$ Immediately,

$$
\Re=-f\left(\frac{-\mu}{\sigma_{t+1 \mid t}}\right)\left(\frac{\mu}{\sigma_{t+1 \mid t}^{2}}\right),
$$

where $f(\cdot)$ is the probability density function (p.d.f.) of standardized returns.

In Figure 2, we work in a Gaussian environment and plot $\Re$ as a function of the information ratio, $\mu / \sigma$. Note that $\Re$ is always negative (i.e., the probability of a positive return is always decreasing in the conditional standard deviation). Crucially, however, $\Re$ is not monotone in $\mu / \sigma$; instead, it achieves a minimum at $\mu / \sigma=\sqrt{2}=1.41$. This makes sense: for $\mu / \sigma$ close to zero, the conditional probability of a positive return can deviate little from $1 / 2$, and hence responsiveness is tiny. Similarly, for very large $\mu / \sigma$, the conditional probability of a positive return can deviate little from 1 , and hence responsiveness is again tiny. Intermediate values of $\mu / \sigma$, however, can produce greater responsiveness. The maximal forecastability as measured by $\Re$ that occurs when $\mu / \sigma \approx 1.41$ is rather high for an information ratio. The frequency with which we hit that "sweet spot" depends on the volatility of volatility, to which we shall return.

\subsection{The Correlation between Sign Forecasts and Realizations}

To characterize the correlation between sign forecasts and realizations, first note that

$$
\begin{aligned}
\operatorname{Cov}\left(I_{t+1}, P_{t+1 \mid t}\right) & =E\left(I_{t+1} P_{t+1 \mid t}\right)-E\left(I_{t+1}\right) E\left(P_{t+1 \mid t}\right) \\
& =E\left(I_{t+1} P_{t+1 \mid t}\right)-P^{2},
\end{aligned}
$$

${ }^{6}$ This is also known as the "marginal effect" in the binary response literature.
Figure 2 Responsiveness of Sign Probability to Volatility Movements Plotted Against the Information Ratio, $\mu / \sigma$

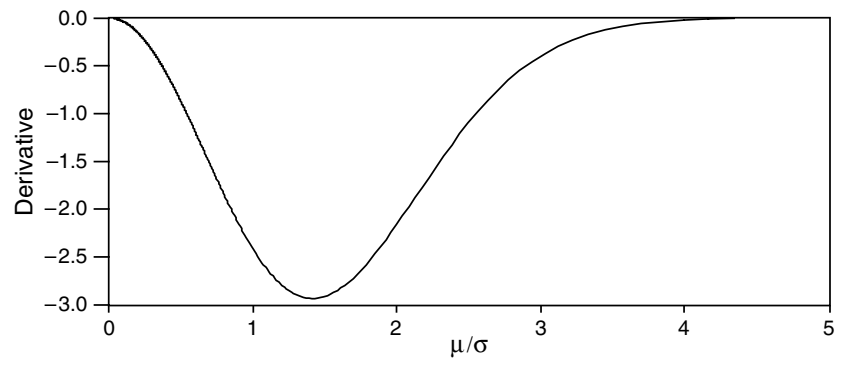

Notes. We plot $\Re_{t}$, the derivative of the probability of a positive return with respect to return volatility, as a function of the information ratio, $\mu / \sigma$. We assume Gaussian returns.

where $P$ is the unconditional probability of a positive return and $I_{t+1}$ is the indicator variable of an ex post realized positive return. Second, use the law of iterated expectations to get

$$
\begin{aligned}
E\left(I_{t+1} P_{t+1 \mid t}\right) & =E\left(E_{t}\left(I_{t+1} P_{t+1 \mid t}\right)\right)=E\left(E_{t}\left(I_{t+1}\right) P_{t+1 \mid t}\right) \\
& =E\left(P_{t+1 \mid t}^{2}\right) .
\end{aligned}
$$

Hence, we have

$$
\operatorname{Cov}\left(I_{t+1}, P_{t+1 \mid t}\right)=E\left(P_{t+1 \mid t}^{2}\right)-P^{2}=\operatorname{Var}\left(P_{t+1 \mid t}\right),
$$

so the covariance between the forecast and the realization is equal to the variance of the forecast. ${ }^{7}$ Converting to correlation, we can write

$$
\begin{aligned}
\operatorname{Corr}\left(I_{t+1}, P_{t+1 \mid t}\right) & =\frac{\operatorname{Var}\left(P_{t+1 \mid t}\right)}{\operatorname{Std}\left(I_{t+1}\right) \operatorname{Std}\left(P_{t+1 \mid t}\right)} \\
& =\frac{\operatorname{Std}\left(P_{t+1 \mid t}\right)}{\sqrt{P(1-P)}},
\end{aligned}
$$

where $P=E\left(I_{t}\right)$. Note that the correlation between sign forecasts and realizations depends only on the standard deviation of the forecast, which, of course, will depend on the particular return process at hand. Despite its generality, the correlation expression furnishes considerable insight. In particular, because the optimal probability forecast $P_{t+1 \mid t}$ is driven entirely by the volatility $\sigma_{t+1 \mid t}$, we have that $\operatorname{Corr}\left(I_{t+1}, P_{t+1 \mid t}\right)$, which is proportional to $\operatorname{Std}\left(P_{t+1 \mid t}\right)$, is therefore driven by the volatility of volatility.

\section{Detecting Sign Forecastability}

Now, we examine questions relevant to the detection of sign forecastability. First, we examine the serial correlation structure of sign realizations, and

${ }^{7}$ Alternatively, and perhaps more intuitively, note that regression of $I_{t+1}$ on $P_{t+1 \mid t}$ yields a unit coefficient by definition of $I_{t+1}$ and $P_{t+1 \mid t}$. That is, $\operatorname{Cov}\left(I_{t+1}, P_{t+1 \mid t}\right) / \operatorname{Var}\left(P_{t+1 \mid t}\right)=1$, which implies that $\operatorname{Cov}\left(I_{t+1}, P_{t+1 \mid t}\right)=\operatorname{Var}\left(P_{t+1 \mid t}\right)$. 
we argue that it is not likely to be useful for identifying sign forecastability because the optimal sign predictor turns out to be highly nonlinear. Hence, linear diagnostic tools discard valuable information. Next, we study the efficacy of runs tests for detecting sign forecastability and show that they have parallel deficiencies. Finally, we examine the ability of traditional market timing tests to detect sign forecastability, and we argue that although they may have good power to detect sign forecastability arising from timevarying expected returns, they have little or no power to detect sign forecastability arising from variation in volatility (or higher-ordered conditional moments).

\subsection{Serial Correlation of Signs}

The basic insight is simply that

$$
\operatorname{Corr}\left(I_{t+1}, I_{t}\right)<\operatorname{Corr}\left(P_{t+1 \mid t}, I_{t+1}\right),
$$

which follows immediately from the fact that the optimal time- $t$ forecast of $I_{t+1}, P_{t+1 \mid t}$ has a higher correlation with $I_{t+1}$ than anything else observed at time $t$, including $I_{t}{ }^{8}$ The inequality leads one to suspectalthough, of course, it does not definitively provethat the size of the sign autocorrelation is likely to be much less than the maximum attainable because $I_{t}$ is not likely to be highly correlated with $P_{t+1 \mid t}$, which is driven directly by $\sigma_{t+1 \mid t}$, not $I_{t}$. Hence, we conjecture that the autocorrelations of the sign sequence may be small, even if sign predictability is high. In §5, we shall provide a quantitative assessment of this effect in a realistically calibrated simulation.

\subsection{Runs Tests}

Working with a 0-1 sign sequence naturally leads one to consider tests of sign forecastability based on the number of runs in the sign sequence, and there is a long tradition of doing so in empirical finance; see, for example, Campbell et al. (1997, Chapter 2) for an overview. We now consider whether runs tests are likely to be more useful for detecting sign dependence than the serial correlation coefficients discussed above.

A run is simply a string of consecutive zeros or ones. Hence, the number of runs is the number of switches from 0 to 1 , plus the number of switches from 1 to 0 , plus 1 ,

$$
N_{\text {runs }}=1+\sum_{t}\left(1-I_{t}\right) I_{t+1}+\sum_{t} I_{t}\left(1-I_{t+1}\right),
$$

which can be written as

$$
N_{\text {runs }}=1+2 \hat{P} T-2 \sum_{t} I_{t} I_{t+1}
$$

${ }^{8}$ The inequality can also be established by formally deriving the equality $\operatorname{Corr}\left(I_{t+1}, I_{t}\right)=\operatorname{Corr}\left(P_{t+1 \mid t}, I_{t+1}\right) \operatorname{Corr}\left(P_{t+1 \mid t}, I_{t}\right)$. where $\hat{P}=(1 / T) \sum_{t} I_{t}$. Solving the $N_{\text {runs }}$ equation for $\sum_{t} I_{t} I_{t+1}$ and exploiting the fact that $I_{t}^{2}=I_{t}$ yields the estimator,

$$
\begin{aligned}
\widehat{\operatorname{Corr}}\left(I_{t+1}, I_{t}\right) & =\frac{(1 / T) \sum_{t} I_{t} I_{t+1}-\hat{P}^{2}}{\widehat{P}(1-\hat{P})} \\
& =1-\frac{N_{\text {runs }}-1}{2 T \hat{P}(1-\hat{P})} .
\end{aligned}
$$

This expression makes clear that there is no information in the number of runs in a sign sequence that is not also in the first-order autocorrelation of the sequence, and conversely. Thus, our earlier conjecture that sign predictability is unlikely to be found using autocorrelations of the sign sequence translates as well into a conjecture that it is unlikely to be found using runs tests. In general, tests that rely only on the sign sequence omit important information about volatility dynamics, which is potentially valuable for detecting sign predictability.

\section{3. $\quad$ Market Timing Tests}

Here, we discuss some popular market timing tests and their relationship to return sign forecasts, and we argue that none of them are likely to be useful for capturing sign forecastability when it arises via volatility dynamics, as we have emphasized.

The literature on market timing is intimately concerned with signs and sign forecasting. For example, Henriksson and Merton (1981) argue that $p_{1}+p_{2}-1$ can be interpreted as the multiplier to apply to the value of perfect market timing, where $p_{1}$ is the probability of a correctly forecasted negative return and $p_{2}$ is the probability of a correctly forecasted positive return. Breen et al. (1989) show that in the regression

$$
I\left(R_{t+1}>0\right)=a+b I\left(P_{t+1 \mid t}>0.5\right)+e_{t+1},
$$

we have that $b=p_{1}+p_{2}-1$. Hence, the absence of Henriksson and Merton (1981) market timing ability corresponds to $b=0$, which is easily tested using standard methods. Cumby and Modest (1987) examine the closely related regression,

$$
R_{t+1}=a+b I\left(P_{t+1 \mid t}>0.5\right)+e_{t+1},
$$

and similarly test the significance of $b .^{9}$

Note that all of the tests above process $P_{t+1 \mid t}$ in a particular way: $P_{t+1 \mid t}$ enters them only through the indicator function $I\left(P_{t+1 \mid t}>0.5\right) .{ }^{10}$ Hence, for example, a $P_{t+1 \mid t}$ of 0.5001 is treated fundamentally differently from a $P_{t+1 \mid t}$ of 0.4999 , whereas a $P_{t+1 \mid t}$ of 0.9999

\footnotetext{
${ }^{9}$ See also Merton (1981), Whitelaw (1997), and Busse (1999). Note, however, that this framework does not include the quadratic regression tests of Treynor and Mazuy (1966) and Ferson and Schadt (1996), which are used in mutual fund performance evaluation.

${ }^{10}$ The same is true for generalizations of the Henriksson and Merton (1981) test, such as Pesaran and Timmermann (1992).
} 
is treated no differently from a $P_{t+1 \mid t}$ of 0.5001 . This is particularly unfortunate because although volatility dynamics lead to sign forecastability (i.e., variation in $\left.P_{t+1 \mid t}\right)$, the time-varying $P_{t+1 \mid t}$ may well never drop below 0.5 . Such is the case, for example, in the leading example of a fixed positive expected return with symmetric conditional density analyzed earlier, so that the tests discussed above would have no power to detect sign dependence. Hence, the traditional market timing tests are best viewed as tests for sign dependence arising from variation in expected returns rather than from variation in volatility (or higher-ordered conditional moments).

\section{Sign Forecasting for Various Data Frequencies and Forecast Horizons: A Simulation Experiment}

We have shown that return sign forecastability arises from the interaction of nonzero expected returns and volatility forecastability. As expected returns approach zero, or as volatility forecastability approaches zero, sign forecastability approaches zero. ${ }^{11}$ Hence, one does not expect strong sign forecastability for very high-frequency returns such as daily, despite their high volatility forecastability, because expected daily returns are negligible. Similarly, one does not expect strong sign forecastability for very low-frequency returns such as annual, despite the high expected returns, because annual return volatility forecastability is negligible. One might therefore conjecture that sign forecastability will be highest at some intermediate horizon between such very short and very long extremes. In this section, we evaluate this conjecture.

When analyzing sign dynamics at various horizons, one is quickly faced with the challenge that few discrete-time dynamic models with time-varying volatility are closed in distribution under increasing horizons. ${ }^{12}$ We therefore work with Heston's (1993) affine continuous-time stochastic volatility model, which is arguably the most widely applied modern univariate stochastic process for equity and equity index returns. In Heston's (1993) model, the conditional characteristic function is known for any horizon, so Fourier inversion techniques can be used to compute sign probability forecasts.

\footnotetext{
${ }^{11}$ Of course, higher-ordered conditional moment dynamics can also contribute to sign predictability, as we discuss in detail in the online supplement.

${ }^{12}$ For penetrating insight into the difficulties involved in the temporal aggregation of discrete-time volatility models, see Meddahi and Renault (2004), Meddahi (2001), Darolles et al. (2001), and Heston and Nandi (2000).
}

\subsection{Simulation Design}

The stochastic volatility model parsimoniously captures many of the stylized facts of asset returns, including skewness, leptokurtosis, and volatility persistence, and its conditional density can be calculated easily at any forecast horizon. For all of these reasons-both substantive and methodological-it has become a standard benchmark in empirical asset pricing. ${ }^{13}$

The Heston (1993) stochastic volatility model is

$$
\begin{gathered}
d S(t)=\mu S d t+\sigma(t) S d z_{1}, \\
d \sigma^{2}(t)=\kappa\left(\theta-\sigma^{2}(t)\right) d t+\eta \sigma(t) d z_{2},
\end{gathered}
$$

where $S(t)$ is the asset price process and $\sigma^{2}(t)$ is the variance process, and where $\operatorname{Corr}\left(d z_{1}, d z_{2}\right)=\rho$. The expected instantaneous rate of return is $\mu$, the longrun variance is $\theta$, the speed of variance adjustment is governed by $\kappa$, and the volatility of volatility is governed by $\eta$.

Using Ito's lemma, the stochastic volatility process can conveniently be written in terms of the log asset price, $x(t)$, as

$$
\begin{gathered}
d x(t)=\left(\mu-\sigma^{2}(t) / 2\right) d t+\sigma(t) d z_{1}, \\
d \sigma^{2}(t)=\kappa\left(\theta-\sigma^{2}(t)\right) d t+\eta \sigma(t) d z_{2} .
\end{gathered}
$$

Note that although the instantaneous drift is simply a constant, the continuously compounded return has a slightly time-varying mean from the Ito transformation.

The probability of an increase in the asset price between time $t$ and $t+\tau$, or equivalently, the probability of a positive return during $[t, t+\tau]$, can be calculated using the inverse characteristic function technique. ${ }^{14}$ In particular,

$$
\begin{aligned}
P_{t+\tau \mid t} & \equiv \operatorname{Pr}\left(x(t+\tau) \geq x(t) \mid x(t)=x, \sigma^{2}(t)=\sigma^{2}\right) \\
& =\frac{1}{2}+\frac{1}{\pi} \int_{0}^{\infty} \operatorname{Re}\left(\frac{\exp (-i \psi x) f\left(x, \sigma^{2}, \tau ; \psi\right)}{i \psi}\right) d \psi,
\end{aligned}
$$

where $f\left(x, \sigma^{2}, \tau ; \psi\right)$ is the characteristic function for horizon $\tau, i=\sqrt{-1}, \operatorname{Re}(\cdot)$ takes the real part of a complex number, and the characteristic function is

$$
f\left(x, \sigma^{2}, \tau ; \psi\right)=\exp \left(C(\tau, \psi)+D(\tau, \psi) \sigma^{2}+i \psi x\right),
$$

${ }^{13}$ The stochastic volatility model has been estimated by Andersen et al. (2002), Bakshi et al. (1997), Benzoni (2002), Chernov et al. (2003), Chernov and Ghysels (2000), Eraker et al. (2003), Jones (2003), and Pan (2002), among others. We intentionally work with a very simple version of the model, with a single volatility factor, no volatility jumps, and no volatility long memory. One could, of course, examine even richer models with multiple volatility factors and/or volatility jumps as in Alizadeh et al. (2002), Bates (2000), Chernov et al. (2003), and Duffie et al. (2000), and long memory in volatility as in Andersen et al. (2001a, b; 2003).

${ }^{14}$ As in the Gaussian case, computation of the sign probability requires numerical integration, but the well-behaved integrand renders the integration straightforward. 
where

$$
\begin{gathered}
C(\tau, \psi)=\mu \psi i \tau+\frac{\kappa \theta}{\eta^{2}}((\kappa-\rho \eta \psi i+d) \tau \\
\left.-2 \log \left(\frac{1-g \exp (d \tau)}{1-g}\right)\right), \\
D(\tau, \psi)=\left(\frac{\kappa-\rho \eta \psi i+d}{\eta^{2}}\right)\left(\frac{1-\exp (d \tau)}{1-g \exp (d \tau)}\right) \\
g=\frac{\kappa-\rho \eta \psi i+d}{\kappa-\rho \eta \psi i-d}
\end{gathered}
$$

and

$$
d=\sqrt{(\rho \eta \psi i-\kappa)^{2}+\eta^{2}\left(\psi i+\psi^{2}\right)} .
$$

As we have shown, the structure of the Heston model makes certain key calculations tractable, which explains its popularity. We will now exploit that tractability to illustrate several important aspects of optimal sign forecasting, including the existence of a nontrivial optimal horizon for sign prediction. Before doing so, however, we note that the Heston model actually limits the possible amount of sign predictability. In particular, to ensure in discrete-time simulations that the variance process stays strictly positive almost surely in the Heston model, it is necessary to restrict the volatility of volatility $(\eta)$, such that $\eta^{2} \leq$ $2 \theta \kappa$. This limits the amount of sign predictability that the Heston model can generate because it requires the volatility of volatility to be small relative to the unconditional variance and the conditional variance persistence, whereas sign predictability is greatest when the volatility of volatility is high, when conditional variance persistence is high, and when the unconditional variance is low relative to the mean. Other stochastic volatility specifications, although less tractable mathematically, imply no such limits to sign predictability. ${ }^{15}$ In this sense, then, our simulation results below on sign predictability using the Heston model as a datagenerating process are, if anything, conservative relative to those that could be obtained using alternative models.

We simulate prices at five-minute intervals and assume 24-hour trading with 250 trading days per year. For the purpose of sign prediction, we proceed by discarding the intraday observations and take daily to be the highest frequency of interest. We calibrate the parameters to typical values estimated in the empirical literature. Our benchmark values are $\mu=0.10, \kappa=2, \theta=0.015, \eta=0.15$, and $\rho=-0.50$,

\footnotetext{
${ }^{15}$ The volatility of volatility restriction in the Heston (1993) model has been found to be restrictive in option valuation as well. Circumventing the restriction, Duffie et al. (2000) suggest a model with correlated jumps in returns and jumps in volatility. Bakshi and Cao (2003) find that the new model significantly improves on the Heston (1993) model when valuating individual equity options.
}

which imply a daily mean of about $0.037 \%$, a daily unconditional standard deviation of $0.77 \%$, unconditional skewness of about -0.1 , and unconditional excess kurtosis of about $1 .^{16}$ The annualized mean reversion parameter $\kappa=2$ implies a daily persistence of about $1-2 / 250=0.99$ in a standard $\operatorname{GARCH}(1,1)$ model. Note also that the parameters satisfy the $\eta^{2} \leq$ $2 \theta \kappa$ condition.

\subsection{Simulation Results}

In Figure 3, we plot the sign forecasts from a typical sample path of the simulated process, computed using (19). We show daily, weekly, monthly, quarterly, semiannual, and annual conditional as well as unconditional sign probabilities. As we move from daily to annual returns, the volatility of the conditional sign probabilities first increases and then decreases. By (10), this supports our conjecture that sign predictability should increase and then decrease with horizon. In contrast, the unconditional probability of a positive return increases monotonically (and at a decreasing rate) with horizon.

In Figure 4, we focus more directly and thoroughly on our conjecture that sign dynamics will be most prevalent at intermediate frequencies; examining the correlation between sign forecasts and realizations as a function of horizon. Consider first the top line where $\mu=0.10$, which is our benchmark parameter value. The correlation is quite low for the highest frequency returns, then it increases, and then it tapers off again as we aggregate toward annual returns. The correlation is highest at horizons of approximately 2-3 months (corresponding to 40-60 trading days). Interestingly, then, despite the fact that sign predictability is driven by volatility predictability, which is highest at very high frequencies, the interaction between decreasing volatility predictability and increasing expected returns under temporal aggregation results in maximization of sign predictability at medium horizons.

Consider now the middle and lower lines in Figure 4 corresponding to $\mu=0.05$ and $\mu=0$, respectively, with all other parameters kept at their benchmark values. As expected, signs are less forecastable at all horizons for smaller $\mu$; the figure provides a precise quantitative characterization. Interestingly, some sign forecastability remains even when $\mu=0$ because of the nonzero leverage effect, $\rho$, interacting with the volatility dynamics. ${ }^{17}$

\footnotetext{
${ }^{16}$ In the online supplement, we explore an alternative parameterization with no leverage, and the results are qualitatively similar.

${ }^{17}$ It is interesting to note that even when both drift and leverage are zero, there is a small degree of sign forecastability as the horizon increases, coming from the Ito term, $-\sigma^{2}(t) / 2$, in the drift of the $\log$ price process. Meddahi and Renault (2004) find similar effects
} 
Figure 3 Time Series of Conditional Sign Probabilities-Various Return Horizons
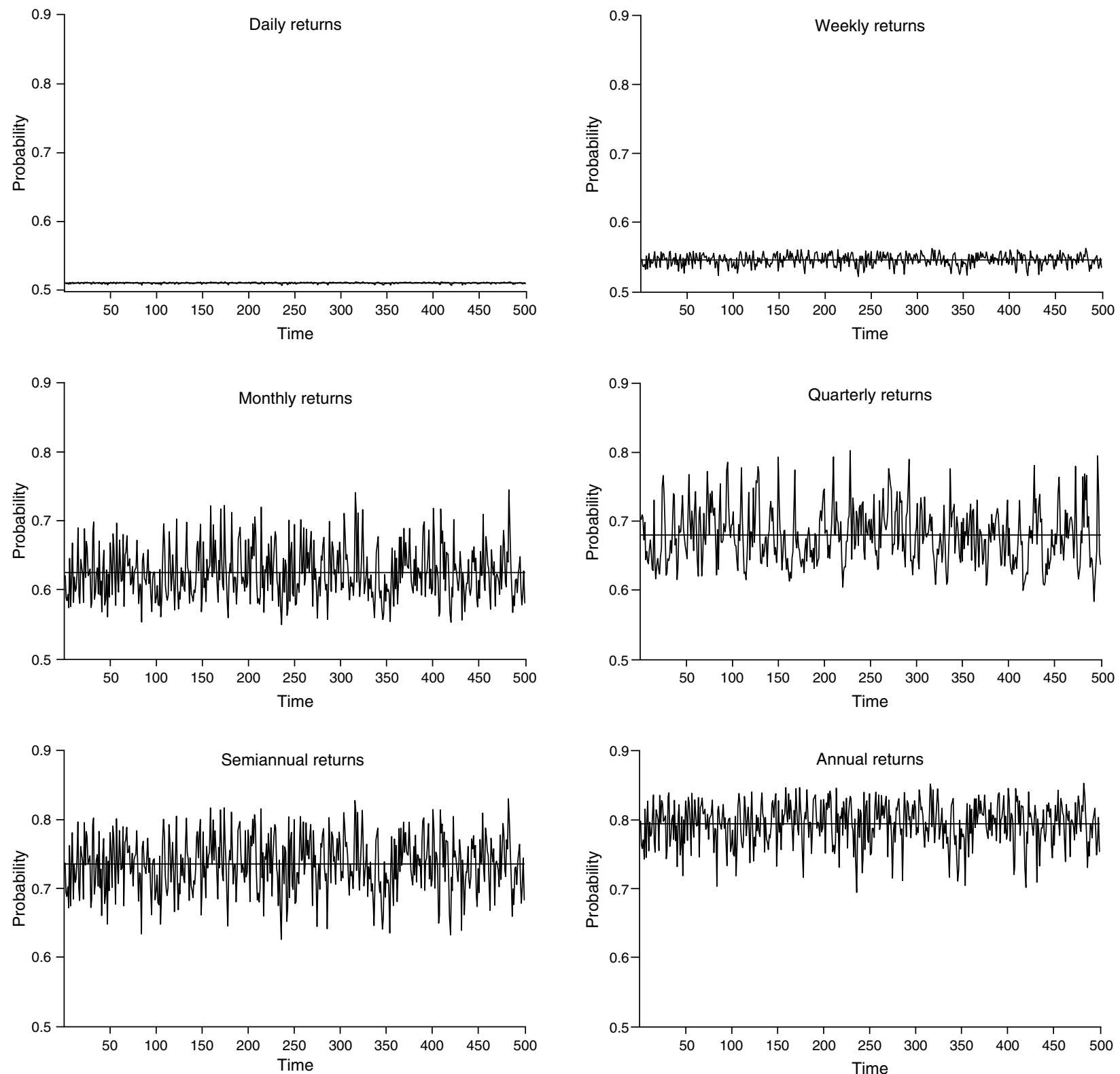

Notes. We simulate asset prices from a stochastic volatility model parameterized as $d S(t)=0.10 S d t+\sigma(t) S d z_{1}$ and $d \sigma^{2}(t)=2\left(0.015-\sigma^{2}(t)\right) d t+$ $0.15 \sigma(t) d z_{2}$, with $\operatorname{Corr}\left(d z_{1}, d z_{2}\right)=-0.5$. We then calculate at each of 500 periods the conditional probability of a positive return at daily, weekly, monthly, and annual horizons. The horizontal line in each subplot denotes the unconditional probability of a positive return, which equals the average conditional probability.

In Figure 5, we explore the effects of lower volatility persistence. The top line again corresponds to our benchmark parameter value; that is, $\kappa=2$. The middle line shows the correlation between sign forecasts and realizations when $\kappa=5$ (corresponding to a daily volatility persistence of about 0.98 ) and the bottom line when $\kappa=10$ (corresponding to a daily volatility

arising under aggregation. By defining $d S(t) / S(t)$ to have a symmetric distribution, an asymmetry is automatically introduced in the distribution of $S(t+\tau)$. See the online supplement for further details. persistence of about 0.96), with all other parameters kept at their benchmark values. As expected, signs are less forecastable at all horizons for lower volatility persistence, and the figure again provides a precise quantitative characterization.

In Figure 6, we show another important result, also suggested but not conclusively established by our earlier analytic work: the simple autocorrelation of the sign realization is small compared to the correlation between the forecasted and realized signs, at all horizons, suggesting that attempts to detect, model, or forecast signs by simple linear autoregressive models 
Figure 4 Correlation Between Sign Forecasts and Realizations Across Horizons-Various Expected Return Parameters

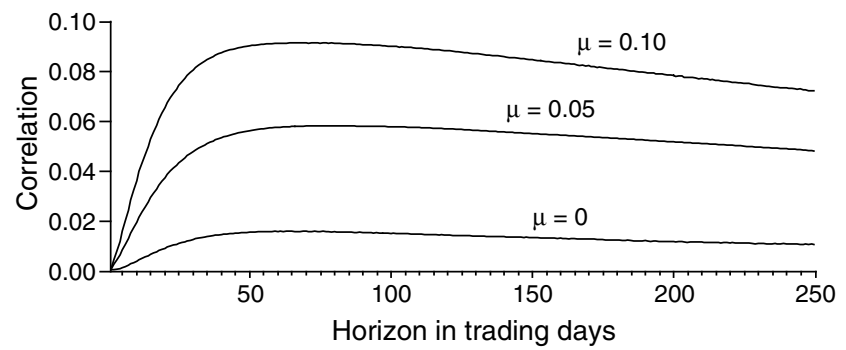

Notes. We simulate asset prices from a stochastic volatility model parameterized as $d S(t)=\mu S d t+\sigma(t) S d z_{1}$ and $d \sigma^{2}(t)=2\left(0.015-\sigma^{2}(t)\right) d t+$ $0.15 \sigma(t) d z_{2}$, with $\operatorname{Corr}\left(d z_{1}, d z_{2}\right)=-0.5$ and $\mu=0.10,0.05$, and 0.00 , respectively. We then calculate the ex ante conditional probability of a positive return as well as the ex post return sign realization at nonoverlapping horizons ranging from 1 to 250 trading days (one year). We calculate the sample correlation between the forecast and the realization across a large number of realizations, making use of the quasi-analytic result (10) in the text.

Figure 5 Correlation Between Sign Forecasts and Realizations Across Horizons-Various Volatility Persistence Parameters

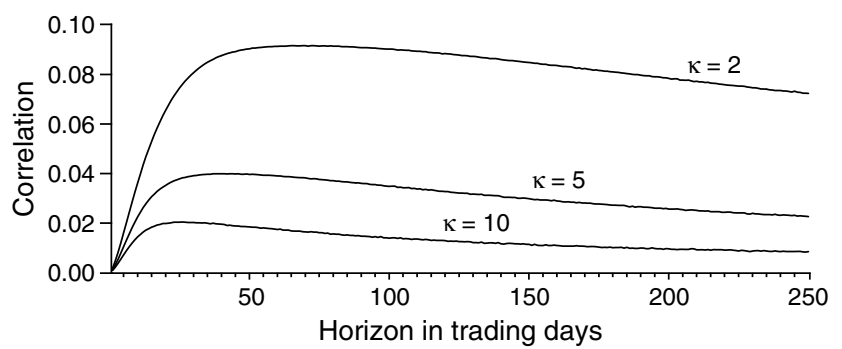

Notes. We simulate $d S(t)=0.10 S d t+\sigma(t) S d z_{1}$ and $d \sigma^{2}(t)=\kappa(0.015-$ $\left.\sigma^{2}(t)\right) d t+0.15 \sigma(t) d z_{2}$, with $\operatorname{Corr}\left(d z_{1}, d z_{2}\right)=-0.5$, and with volatility persistence parameter $\kappa=2,5$, and 10 , respectively. We then calculate the ex ante conditional probability of a positive return as well as the ex post return sign realization at nonoverlapping horizons ranging from 1 to 250 trading days (one year). We calculate the sample correlation between the forecast and the realization using a large number of realizations, making use of the quasi-analytic result (10) in the text.

Figure 6 Correlation Between Sign Forecasts and Realizations and First Autocorrelation of Return Signs-Various Horizons, Benchmark Parameters

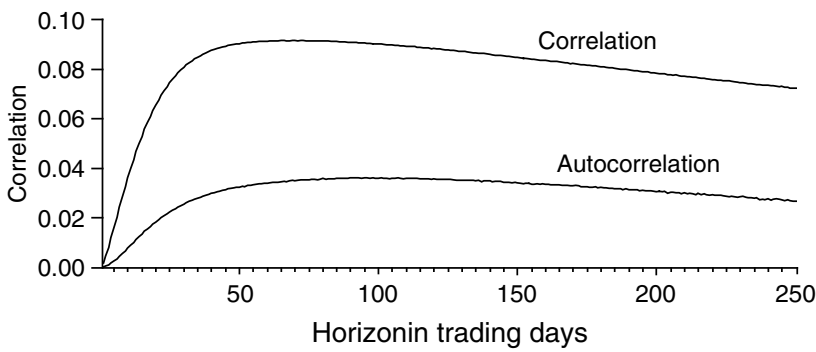

Notes. The correlation between sign forecasts and realizations is as in Figure 4 . We compute the first autocorrelation of the sign sequence by simulating asset prices from a stochastic volatility model parameterized as $d S(t)=$ $0.10 S d t+\sigma(t) S d z_{1}$ and $d \sigma^{2}(t)=2\left(0.015-\sigma^{2}(t)\right) d t+0.15 \sigma(t) d z_{2}$, with $\operatorname{Corr}\left(d z_{1}, d z_{2}\right)=-0.5$. We then construct an indicator sequence of return signs for each horizon, and we calculate the sample autocorrelation from a long simulated sequence of returns, using the quasi-analytic result (10) in the text.
Figure 7 Responsiveness of Sign Probability to Volatility Movements in Heston's (1993) Stochastic Volatility Model Plotted Against the Information Ratio, $\mu / \sigma$

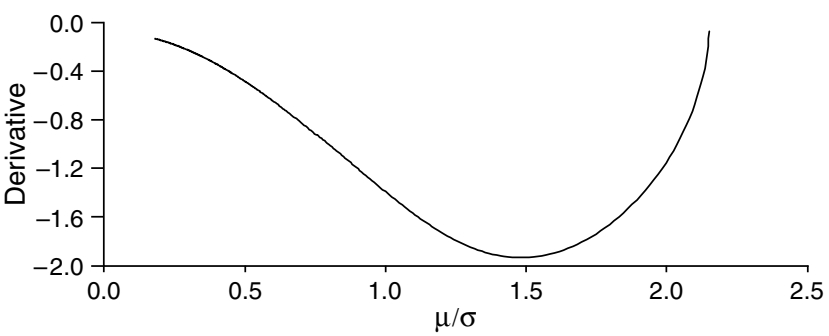

Notes. We take the numerical derivative of the conditional probability, $P_{t+\tau \mid t}$, from Heston's (1993) stochastic volatility model with respect to the standard deviation $\sigma(t)$. We plot this derivative against the annualized information ratio, $\mu / \sigma_{t+\tau \mid t}$, where $\mu$ is the annualized drift and $\sigma_{t+\tau \mid t}$ is the annualized expected average standard deviation over the forecast horizon, $\tau$. We use the benchmark parameters from Figure 6 , with a forecast horizon of 40 trading days $(\tau=40 / 250)$.

are not likely to be fruitful. It appears that the nonlinear volatility dynamics that drive sign dynamics make the linear forecastability in signs quite small. In our setup, tomorrow's sign is linked to tomorrow's volatility, which is much more correlated with today's volatility than with today's sign.

Finally, in Figure 7, we take the numerical derivative of the conditional probability, $P_{t+\tau \mid t}$, in Equation (19) with respect to the standard deviation $\sigma(t)$. We plot this derivative against the annualized information ratio defined as $\mu / \sigma_{t+\tau \mid t}$, where $\mu=0.1$ is the (annualized) mean of the instantaneous return drift and $\sigma_{t+\tau \mid t}$ is the annualized expected average standard deviation over the forecast horizon, $\tau .{ }^{18}$ We use the benchmark parameters from Figure 6, with a forecast horizon of 40 days $(\tau=40 / 250)$. Figure 7 thus confirms in a richer environment the result found in the stylized Gaussian model in Figure 2. In particular, in a dynamic volatility setting when volatility is very low, the sign probability does not respond to changes in volatility-it is simply 1 . Similarly, when the volatility is very high, it dominates the mean return, and the sign probability remains near $1 / 2$. However, for intermediate levels of volatility, the sign probability responds to changes in volatility. Specifically, in this case, when $\mu / \sigma_{t+\tau \mid t}$ is close to 1.5 ; that is, when $\sigma_{t+\tau \mid t}$ is close to $6.67 \%$ in annual terms, the sign predictor reaches a maximum level of responsiveness to volatility changes. Figure 7 thus shows that the "sweet spot" for sign forecast responsiveness to volatility changes is found at a low but not completely unrealistic level of volatility.

${ }^{18}$ Note that the expected average variance in the Heston (1993) model can be calculated from $\sigma_{t+\tau \mid t}^{2}=\theta+(1-\exp (-\kappa \tau))$ / $(\kappa \tau)\left(\sigma^{2}(t)-\theta\right)$. 


\section{Empirics}

We now present a simple empirical example, producing daily sign forecasts of returns on the S\&P 500 index (SPINDX, from the Center for Research in Security Prices (CRSP)) from January 1, 1963 through December 31, 2003, at horizons ranging from $h=1$ through $h=250$ days. ${ }^{19}$ The example illustrates our methods, provides preliminary evidence as to their applied relevance, and lays the groundwork for additional exploration.

Let $R_{t+1: t+h}$ be the $h$-day return, and define the "positive return" indicator as $I_{t+h}=1$ if $R_{t+1: t+h}>0$ and $I_{t+h}=0$ otherwise. We want to forecast $I_{t+h}$, and our earlier theoretical analysis strongly suggests using a model of the form

$$
I_{t+h}=F\left(\frac{\mu}{\sigma_{t}}\right)+e_{t+h}
$$

where $F(\cdot)$ is a monotone function with a left limit of zero and a right limit of one, $\mu$ is the $h$-day expected return, and $\sigma_{t}$ is a forecast of $h$-day return volatility. An obvious choice of $F(\cdot)$ is the logistic,

$$
F(x)=\frac{\exp (x)}{1+\exp (x)}
$$

which produces the popular logistic regression (logit) model.

Hence, we proceed via logistic regression of $I_{t+h}$ on $1 / \sigma_{t}$. The issue remains as to what to use for $\sigma_{t}$; indeed, as we have shown and stressed, the key ingredient of a sign forecast is a volatility forecast. Volatility forecasts can be obtained using a variety of approaches, including GARCH volatilities, stochastic volatilities, implied volatilities, and realized volatilities, as surveyed in Andersen et al. (2005b, c). Here, we proceed using the popular RiskMetrics approach, which has links not only to the traditional GARCH approach, but also to the more recent "realized volatility" models of Hsieh (1991) and Andersen et al. (2003), measuring any day's variance (and forecasting any future day's variance) as an exponentially weighted moving average of past daily squared returns, with the customary smoothing parameter of $0.94 .^{20}$

Each day we compute out-of-sample one-day through 250-day return sign probability forecasts

\footnotetext{
${ }^{19}$ We do not include dividends, because SPINDX does not. In addition, we do not subtract a risk-free rate. Doing so would require complete daily term structure data for every day since 1963. It would, of course, be of interest to move to excess returns, including dividends in subsequent more elaborate investigations.

${ }^{20}$ In future work, it would be of interest to contrast the results reported below with those produced using other volatility models. In particular, certain of our empirical results may be driven by the fact that RiskMetrics volatility forecasts do not mean revert, whereas those from most other models do.
}

Figure 8 Daily RiskMetrics Volatility (Annualized)

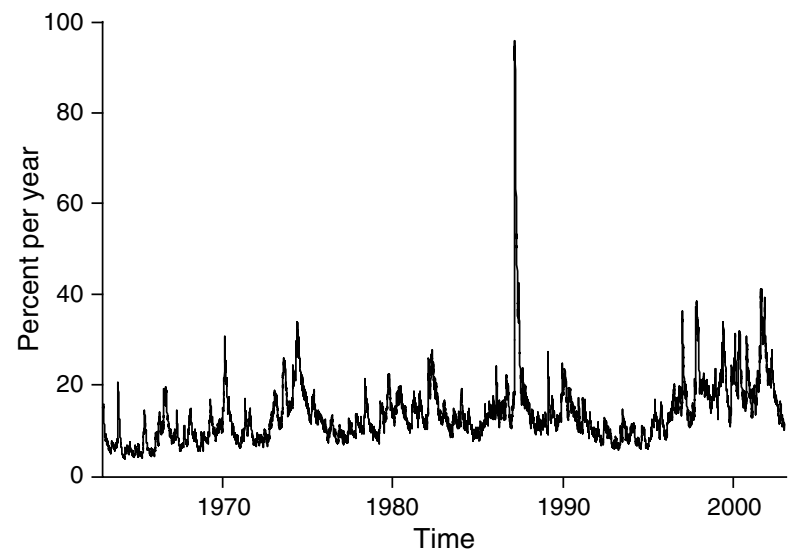

Note. We show the time series of daily (annualized) RiskMetrics volatilities from January 1, 1963 through December 31, 2003, obtained using the standard smoothing parameter of 0.94 .

using five-year rolling estimation windows and different logit models for each horizon to allow expected returns to change over time and horizon. ${ }^{21}$ In Figure 8, we show the volatility series. Its well-known pronounced fluctuations and high persistence are immediately apparent. The key issue, of course, is whether the pronounced and predictable volatility dynamics translate empirically into similarly pronounced and predictable sign dynamics, as in the earlier simulation exercise.

The results are encouraging. In Figure 9, we show the conditional sign probability forecasts for the same six horizons as in the simulations, together with unconditional probabilities superimposed for visual reference. The unconditional sign probabilities naturally increase with horizon, and the conditional sign probabilities fluctuate widely and persistently around them-indeed noticeably more so than in the simulation example-reflecting the wide and persistent empirical fluctuations in S\&P 500 volatility.

In Figure 10, we show the correlation between the out-of-sample sign probability forecast and the sign realization, as well as the first-order autocorrelation of the sign realization for various horizons. The humped patterns, with the correlations larger than the autocorrelations, conform roughly to the theory. It is interesting to note, however, that both the correlations and the autocorrelations are generally much larger than in our earlier simulation example, which uses an affine volatility model with low volatility of volatility.

\section{Concluding Remarks and Directions for Future Research}

Our contribution is twofold. First, we show that given the widely accepted volatility dynamics in stock

${ }^{21}$ All told, we estimate roughly 100,000 logit models. 
Figure 9 Conditional Probability Forecasts-Various Horizons
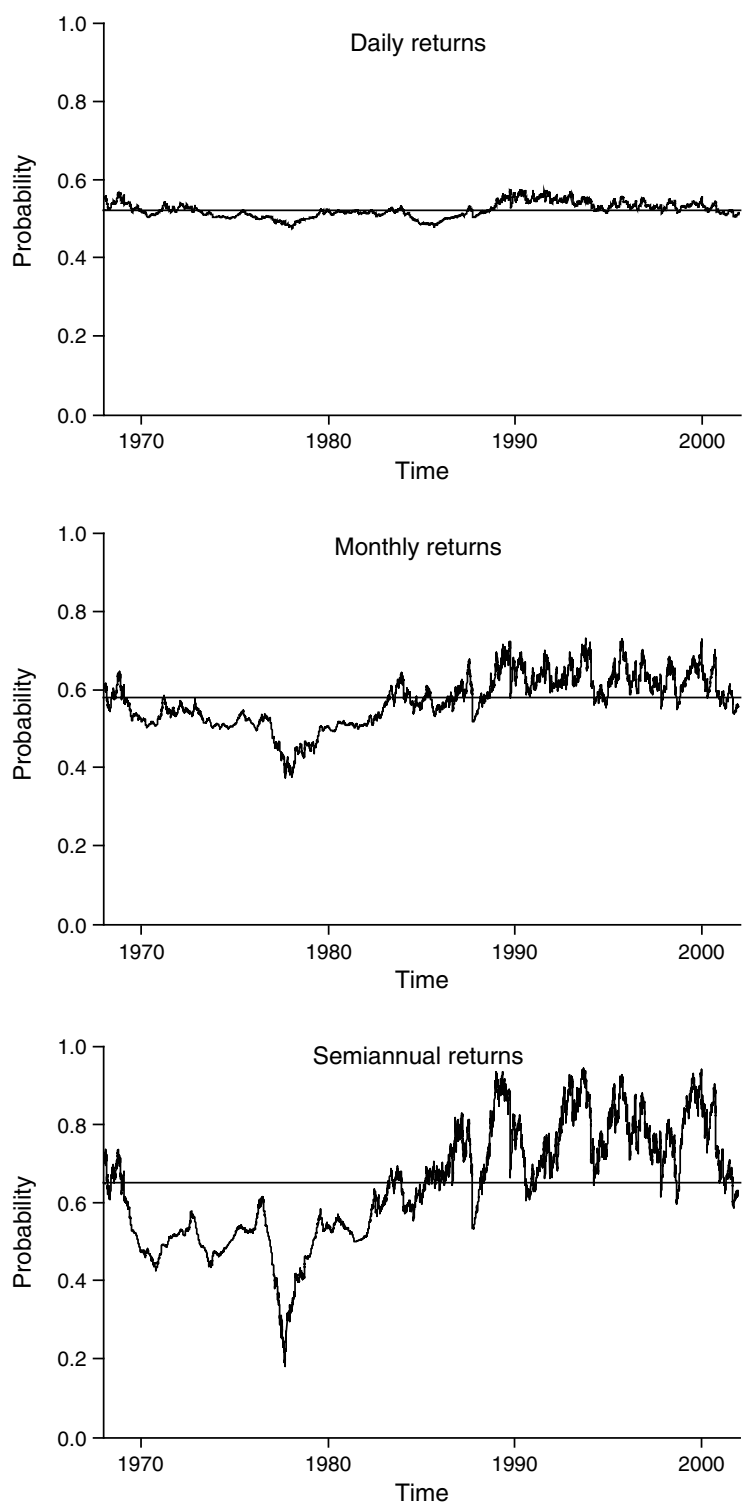
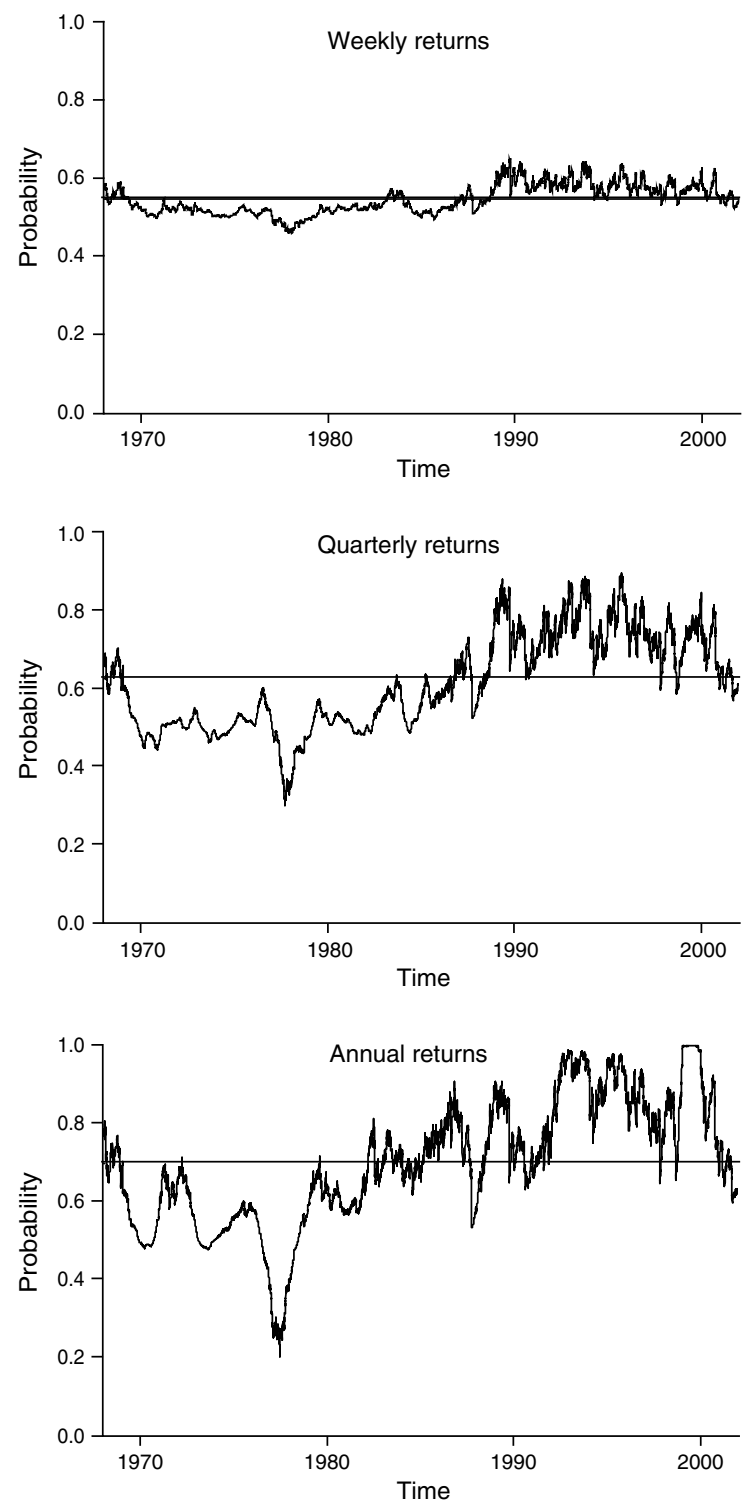

Note. We show the time series of conditional probabilities of a positive S\&P 500 return at six horizons, assessed using a logit model in conjunction with a RiskMetrics volatility forecast.

returns, one should not be surprised to find sign forecastability in returns, even if returns are conditional mean independent. Hence, sign dependence is likely widespread, but it is not necessarily indicative of time-varying expected returns and should not be interpreted as such.

Second, we explore a variety of aspects of sign forecastability, analytically, numerically, and empirically. For example, we show analytically that sign probability forecasts are most sensitive to changes in volatility when volatility is at an intermediate level, and we show in a realistically calibrated simulation exercise that sign forecastability appears strongest at intermediate horizons of two or three months. In addition, we show that the nonlinear nature of sign dependence makes it unlikely to be found via tradi- tional approaches such as analysis of sign autocorrelations, runs tests, or market timing tests.

Importantly, our results relate not only to academic concerns, but also to those of practitioners, who commonly use market timing strategies linked to volatility movements, as documented, for example, in Rattray and Balasubramanian (2003) and Gross et al. (2003). To the best of our knowledge, however, we are the first to provide a rigorous scientific investigation of the links between volatility dynamics and directional market movements.

As for future work, the obvious next step is to formulate trading strategies based on sign forecasts (e.g., by trading digital options) and to assess their efficacy in generating positive risk-adjusted excess returns. Interestingly, the analysis of this paper makes clear 


\section{Figure 10 Forecast Correlation and Return Sign Autocorrelation- Various Horizons}

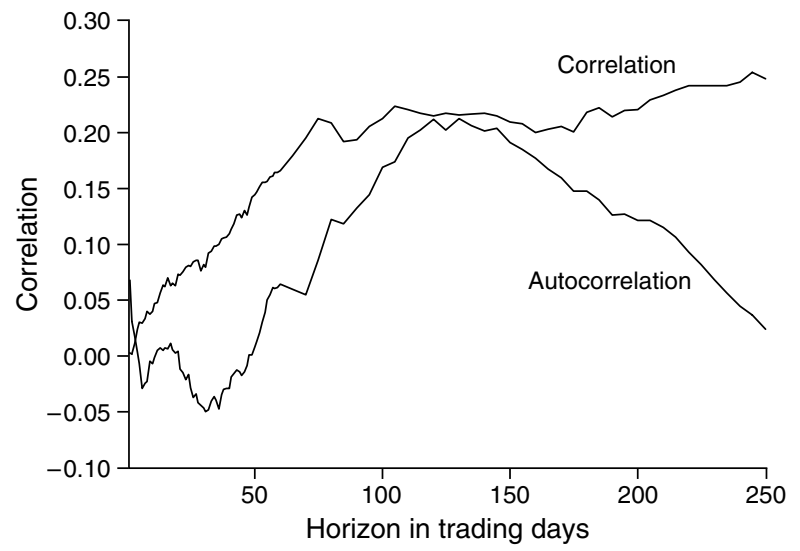

Note. We show the empirical analog of Figure 6 based on probability forecasts produced using a logit model in conjunction with a RiskMetrics volatility forecast.

that such strategies should be related to "volatility timing" strategies, such as those of Fleming et al. (2001, 2003) and Johannes et al. (2002), in which portfolio shares are dynamically adjusted based on forecasts of the variance-covariance matrix of the underlying assets. Sign/volatility dynamics could also be exploitable in safety-first problems, as in Roy (1952), Bawa (1978), and Hagigi and Kluger (1987). One could progress significantly, moreover, by incorporating skewness and kurtosis dynamics, using the methods of El Babsiri and Zakoian (2001). Such "moment timing" will require evaluation measures more widely applicable than simple Sharpe ratios, such as Stutzer's (2001) portfolio performance index.

Other explorations may also prove interesting. One example is generation of probability forecasts for future returns exceeding any given value $x$ or percentile $\alpha$, and developing the links to related work such as Engle and Manganelli (2002) and Taylor (2005). Another example is estimating nonparametrically the maximally predictable nonlinear function $f(\cdot)$ of returns. The results of Chen et al. (2000) indicate that the optimal function will be monotone, as is the sign function, but the issue remains open as to whether and how the maximally predictable nonlinear function of returns diverges from the sign function.

An online supplement to this paper is available on the Management Science website (http://mansci.pubs. informs.org/ecompanion.html).

\section{Acknowledgments}

This work was supported by the National Science Foundation, the Guggenheim Foundation, the Wharton Financial Institutions Center, FQRSC, IFM2, and SSHRC. For helpful comments, the authors thank David Hsieh and two anonymous referees, as well as David Bates, Antulio Bomfim, Michael Brandt, Xiaohong Chen, Michel Dacorogna,
Graham Elliott, Rene Garcia, Christian Gourieroux, Clive Granger, Anthony Hall, Wolfgang Härdle, Joanna Jasiak, Michael Johannes, Blake LeBaron, Bruce Lehman, Martin Lettau, Nour Meddahi, Theo Nijman, Jonathan Reeves, Sergei Sarkissian, Frank Schorfheide, Allan Timmermann, Harald Uhlig, Pietro Veronesi, Ken West, Hal White, Jonathan Wright, and seminar participants at the European Central Bank, the Federal Reserve Board, McGill University, University of California at San Diego, University of Pennsylvania, the Third Annual Conference on Financial Econometrics at the University of Waterloo, the Econometric Society Winter Meetings in Washington, D.C., the NBER/NSF Time Series Meeting in Philadelphia, the New York University Stern Conference in Honor of the 2003 Nobel Prize in Economics, the Northern Finance Association annual meetings, the European Finance Association annual meetings, Singapore Management University, and the Federal Reserve Bank of St. Louis. Sean Campbell, Chayawat Ornthanalai, and Clara Vega provided outstanding research assistance. All inadequacies are ours alone.

\section{References}

Abel, A. 1988. Stock prices under time-varying dividend risk. J. Monetary Econom. 22 375-393.

Alizadeh, S., M. W. Brandt, F. X. Diebold. 2002. Range-based estimation of stochastic volatility models. J. Finance 57 1047-1092.

Andersen, T. G., L. Benzoni, J. Lund. 2002. Estimating jumpdiffusions for equity returns. J. Finance 57 1239-1284.

Andersen, T. G., T. Bollerslev, F. X. Diebold. 2005a. Parametric and nonparametric volatility measurement. L. P. Hansen, Y. AitSahalia, eds. Handbook of Financial Econometrics. North-Holland, Amsterdam, The Netherlands. Forthcoming.

Andersen, T. G., T. Bollerslev, P. F. Christoffersen, F. X. Diebold. 2005b. Volatility and correlation forecasting. G. Elliott, C. W. J. Granger, A. Timmermann, eds. Handbook of Economic Forecasting. North-Holland, Amsterdam, The Netherlands. Forthcoming.

Andersen, T. G., T. Bollerslev, P. F. Christoffersen, F. X. Diebold. 2005c. Practical volatility and correlation modeling for financial market risk management. M. Carey, R. Stulz, eds. Risks of Financial Institutions. University of Chicago Press, Chicago, IL. Forthcoming.

Andersen, T. G., T. Bollerslev, F. X. Diebold, H. Ebens. 2001a. The distribution of realized stock return volatility. J. Financial Econom. 61 43-76

Andersen, T. G., T. Bollerslev, F. X. Diebold, P. Labys. 2001b. The distribution of realized exchange rate volatility. J. Amer. Statist. Assoc. 96 42-55.

Andersen, T. G., T. Bollerslev, F. X. Diebold, P. Labys. 2003. Modeling and forecasting realized volatility. Econometrica 71 579-626.

Backus, D., A. Gregory. 1993. The relations between risk premia and conditional variances. J. Bus. Econom. Statist. 11 177-185.

Baillie, R. T., R. P. DeGennaro. 1990. Stock returns and volatility. J. Financial Quant. Anal. 25 203-214.

Bakshi, G., C. Cao. 2003. Risk-neutral kurtosis, jumps and option pricing: Evidence from 100 most actively traded firms on the CBOE. Working paper, University of Maryland, College Park, MD.

Bakshi, G., C. Cao, Z. Chen. 1997. Empirical performance of alternative option pricing models. J. Finance 52 2003-2049.

Bates, D. 2000. Post-' 87 crash fears in the S\&P 500 futures option market. J. Econometrics 94 181-238. 
Bawa, V. S. 1978. Safety-first, stochastic dominance, and optimal portfolio choice. J. Financial Quant. Anal. 13 255-271.

Benzoni, L. 2002. Pricing options under stochastic volatility: An empirical investigation. Working paper, University of Minnesota, Minneapolis, MN.

Bollerslev, T., R. Y. Chou, K. F. Kroner. 1992. ARCH modeling in finance: A selective review of the theory and empirical evidence. J. Econometrics 52 5-59.

Brandt, M. W., Q. Kang. 2004. On the relationship between the conditional mean and volatility of stock returns: A latent VAR approach. J. Financial Econom. 72 217-257.

Breen, W., L. R. Glosten, R. Jagannathan. 1989. Economic significance of predictable variations in stock index returns. J. Finance 44 1177-1189.

Brock, W. A., C. H. Hommes. 1997. A rational route to randomness. Econometrica 65 1059-1095.

Busse, J. A. 1999. Volatility timing in mutual funds: Evidence from daily returns. Rev. Financial Stud. 12 1009-1041.

Campbell, J. 1987. Stock returns and the term structure. J. Financial Econom. 18 373-399.

Campbell, J., L. Hentschel. 1992. No news is good news: An asymmetric model of changing volatility in stock returns. J. Financial Econom. 31 281-318.

Campbell, J., R. Shiller. 1988. Stock prices, earnings and expected dividends. J. Finance 46 661-676.

Campbell, J., A. W. Lo, A. C. MacKinlay. 1997. The Econometrics of Financial Markets. Princeton University Press, Princeton, NJ.

Chen, X., L. P. Hansen, J. A. Scheinkman. 2000. Principal components and the long run. Working paper, New York University, New York, University of Chicago, Chicago, IL, and Princeton University, Princeton, NJ.

Chernov, M., E. Ghysels. 2000. A study towards a unified approach to the joint estimation of objective and risk neutral measures for the purpose of option valuation. J. Financial Econom. 56 $407-458$.

Chernov, M., A. R. Gallant, E. Ghysels, G. Tauchen. 2003. Alternative models for stock price dynamics. J. Econometrics 116 225-257.

Cheung, Y.-W., M. D. Chinn, A. G. Pascual. 2005. Empirical exchange rate models of the nineties: Are any fit to survive? J. Internat. Money Finance 24 1150-1175.

Christoffersen, P. F., F. X. Diebold. 1996. Further results on forecasting and model selection under asymmetric loss. J. Appl. Econometrics 11 561-572.

Christoffersen, P. F., F. X. Diebold. 1997. Optimal prediction under asymmetric loss. Econometric Theory 13 808-817.

Cumby, R. E., D. M. Modest. 1987. Testing for market timing ability: A framework for forecast evaluation. J. Financial Econom. 19 169-189.

Darolles, S., C. Gourieroux, J. Jasiak. 2001. Compound autoregressive models. Working paper, York University, Toronto, Ontario, Canada.

de Fontnouvelle, P. 2000. Information dynamics in financial markets. Macroeconomic Dynam. 4 139-169.

Duffie, D., J. Pan, K. Singleton. 2000. Transform analysis and asset pricing for affine jump-diffusions. Econometrica 68 1343-1376.

El Babsiri, M., J.-M. Zakoian. 2001. Contemporaneous asymmetry in GARCH processes. J. Econometrics 101 257-294.

Elliott, G., T. Ito. 1999. Heterogeneous expectations and tests of efficiency in the yen/dollar forward foreign exchange market. J. Monetary Econom. 43 435-456.

Engle, R. F., S. Kozicki. 1993. Testing for common features. J. Bus. Econom. Statist. 11 369-380.

Engle, R. F., S. Manganelli. 2002. CAViaR: Conditional autoregressive value at risk by regression quantiles. J. Bus. Econom. Statist. 11 167-176.
Eraker, B., M. Johannes, N. Polson. 2003. The role of jumps in returns and volatility. J. Finance 58 1269-1300.

Fama, E. F. 1970. Efficient capital markets: A review of theory and empirical work. J. Finance 25 383-417.

Fama, E. F. 1991. Efficient capital markets II. J. Finance 46 1575-1617.

Fama, E., K. French. 1988. Dividend yields and expected stock returns. J. Financial Econom. 19 3-29.

Fama, E., K. French. 1989. Business conditions and expected returns on stocks and bonds. J. Financial Econom. 25 23-49.

Ferson, W. E., C. R. Harvey. 1991. The variation of economic risk premiums. J. Political Econom. 99 385-415.

Ferson, W. E., R. W. Schadt. 1996. Measuring fund strategy and performance in changing economic conditions. J. Finance 51 $425-462$.

Fleming, J., C. Kirby, B. Ostdiek. 2001. The economic value of volatility timing. J. Finance 56 329-352.

Fleming, J., C. Kirby, B. Ostdiek. 2003. The economic value of volatility timing using realized volatility. J. Financial Econom. 67 473-509.

Foster, D., T. Smith, R. Whaley. 1997. Assessing goodness-of-fit of asset pricing models: The distribution of the maximal $R^{2}$. J. Finance 52 591-607.

Franses, P. H., D. van Dijk. 2000. Nonlinear Time Series Models in Empirical Finance. Cambridge University Press, Cambridge, UK.

French, K. R., W. Schwert, R. F. Stambaugh. 1987. Expected stock returns and volatility. J. Financial Econom. 19 3-29.

Gencay, R. 1998. Optimization of technical trading strategies and the profitability in security markets. Econom. Lett. 59 249-254.

Gennotte, G., T. A. Marsh. 1993. Variations in economic uncertainty and risk premiums on capital assets. Eur. Econom. Rev. 37 1021-1044.

Ghysels, E., A. Harvey, E. Renault. 1996. Stochastic volatility. G. S. Maddala, C. R. Rao, eds. Statistical Methods in Finance. Handbook of Statistics, Vol. 14. North-Holland, Amsterdam, The Netherlands, 119-191.

Ghysels, E., P. Santa-Clara, R. Valkanov. 2005. There is a risk-return tradeoff after all. J. Financial Econom. 76 509-548.

Glosten, L. R., R. Jagannathan, D. E. Runkle. 1993. On the relation between the expected value and the volatility of the nominal excess return on stocks. J. Finance 48 1779-1801.

Gross, L., J. Keh, S. Leventhal, O. Sarfati. 2003. Individual implied volatility predicts future stock movement. Research report, Equity Derivative Sales, Citigroup, New York.

Hagigi, M., B. Kluger. 1987. Safety first: An alternative performance measure. J. Portfolio Management 13 34-40.

Hansen, B. E. 1994. Autoregressive conditional density estimation. Internat. Econom. Rev. 35 705-730.

Harvey, C. R. 2001. The specification of conditional expectations. J. Empirical Finance 8 573-638.

Harvey, C. R., A. Siddique. 2000. Conditional skewness in asset pricing tests. J. Finance 55 1263-1296.

Henriksson, R. D., R. C. Merton. 1981. On market timing and investment performance II: Statistical procedures for evaluating forecasting skills. J. Bus. 54 513-533.

Heston, S. L. 1993. A closed-form solution for options with stochastic volatility with applications to bond and currency options. Rev. Financial Stud. 6 327-343.

Heston, S. L., S. Nandi. 2000. A closed-form GARCH option valuation model. Rev. Financial Stud. 13 585-625.

Hsieh, D. A. 1991. Chaos and nonlinear dynamics: Application to financial markets. J. Finance 46 1839-1877.

Johannes, M., N. Polson, J. Stroud. 2002. Sequential optimal portfolio performance: Market and volatility timing. Working paper, Columbia University, New York. 
Jones, C. 2003. The dynamics of stochastic volatility: Evidence from underlying and options markets. J. Econometrics 116 181-224.

Kirby, C. 1997. Measuring the predictable variation in stock and bond returns. Rev. Financial Stud. 10 579-630.

Kuan, C.-M., T. Liu. 1995. Forecasting exchange rates using feedforward and recurrent neural networks. J. Appl. Econometrics 10 347-364.

Larsen, G. A., Jr., G. D. Wozniak. 1995. Market timing can work in the real world. J. Portfolio Management 21 74-81.

Leitch, G., J. E. Tanner. 1991. Economic forecast evaluation: Profits versus the conventional error measures. Amer. Econom. Rev. 81 580-590.

Lettau, M., S. Ludvigson. 2005. Measuring and modeling variation in the risk-return tradeoff. Y. Ait-Shalia, L. P. Hansen, eds. Handbook of Financial Econometrics. North-Holland, Amsterdam, The Netherlands.

Leung, M. T., H. Daouk, A.-S. Chen. 2000. Forecasting stock indices: A comparison of classification and level estimation models. Internat. J. Forecasting 16 173-190.

Levich, R. M. 2001. International Financial Markets, 2nd ed. McGrawHill, New York.

Lo, A. W., A. C. MacKinlay. 1999. A Non-Random Walk Down Wall Street. Princeton University Press, Princeton, NJ.

Meddahi, N. 2001. An Eigenfunction approach for volatility modeling. Working paper, University of Montreal, Montreal, Quebec, Canada.

Meddahi, N., E. Renault. 2004. Temporal aggregation of volatility models. J. Econometrics 119 355-379.

Merton, R. C. 1973. An intertemporal capital asset pricing model. Econometrica 41 867-887.

Merton, R. C. 1981. On market timing and investment performance I: An equilibrium theory of value for market forecasts. J. Bus. 54 363-406.

Nelson, C., M. Kim. 1993. Predictable stock returns: The role of small sample bias. J. Finance 48 641-661.

Nelson, D. B. 1991. Conditional heteroskedasticity in asset returns: A new approach. Econometrica 59 347-370.
Pan, J. 2002. The jump-risk premia implicit in options: Evidence from an integrated time-series study. J. Financial Econom. 63 3-50.

Pesaran, H., A. G. Timmermann. 1992. A simple non-parametric test of predictive performance. J. Bus. Econom. Statist. 10 461-465.

Pesaran, M. H., A. G. Timmermann. 1995. Predictability of stock returns: Robustness and economic significance. J. Finance $\mathbf{5 0}$ 1201-1228.

Pesaran, M. H., A. G. Timmermann. 2004. How costly is it to ignore breaks when forecasting the direction of a time series? Internat. J. Forecasting 20 411-425.

Rattray, S., V. Balasubramanian. 2003. The new VIX as a market signal-It still works. Research report, Goldman Sachs, Equity Derivatives Strategy, New York.

Roy, A. D. 1952. Safety-first and the holding of assets. Econometrica 20 431-449.

Rydberg, T. H., N. Shephard. 2003. Dynamics of trade-by-trade price movements: Decomposition and models. J. Financial Econometrics $12-25$.

Stutzer, M. 2001. A portfolio performance index and its implications. Working paper, University of Iowa, Iowa City, IA.

Taylor, J. W. 2005. Generating volatility forecasts from value at risk estimates. Management Sci. 51 712-725.

Treynor, J., K. Mazuy. 1966. Can mutual funds outguess the market? Harvard Bus. Rev. 44 131-136.

Turner, C. M., R. Startz, C. R. Nelson. 1989. A Markov model of heteroskedasticity, risk, and learning in the stock market. J. Financial Econom. 25 3-22.

Wagner, J., S. Shellans, R. Paul. 1992. Market timing works where it matters most: In the real world. J. Portfolio Management 18 86-90.

White, H. 2000. A reality check for data snooping. Econometrica 68 1097-1126.

Whitelaw, R. F. 1997. Time-varying Sharpe ratios and market timing. Working paper, New York University, New York.

Womack, K. L. 1996. Do brokerage analysts' recommendations have investment value? J. Finance 51 137-167. 